\title{
CARRERA ACADÉMICA: ANÁLISIS EMPÍRICO DE SU ESTRUCTURA Y ORGANIZACIÓN EN CHILE
}

\section{Introducción ${ }^{3}$}

Una de las profesiones más dinámicas y de mayor crecimiento actualmente en Chile es la de los profesores que trabajan en el sistema universitario. Debido al acelerado crecimiento de la matrícula, tanto en pre como en posgrado, y al desarrollo de la investigación ha crecido la demanda por académicos adecuadamente preparados. Hasta 2008 sólo en las universidades del Consejo de Rectores ${ }^{4}$ (CRUCH) el número total de docentes comprendía 51.108 (Consejo Superior de Educación, 2008), incluyendo de jornada completa y parcial.

A diferencia de lo ocurrido, por ejemplo, en México en la década de 1970 (Gil Antón, 1994), esta mayor demanda no se ha traducido en la improvisación de profesores mediante el ingreso indiscriminado a la profesión académica de docentes calificados sólo en el nivel de licenciatura. En Chile, la ampliación del mercado académico vino acompañada de mayores exigencias, tales como la posesión del grado académico de doctor (o magíster cuando menos), así como competencias en investigación y administración. Posibles causas de esta particularidad son las políticas de financiamiento estatal, la valorización de la captación de los mejores estudiantes egresados del sistema escolar y los incentivos asociados al quehacer científico y a la investigación (Bernasconi, 2006, 2007).

La profesión académica ha comenzado a ser atractiva para muchos profesionales que ven en ella oportunidades de avanzar a través del cumplimiento de ciertos indicadores de productividad. Además, la trayectoria académica comienza a ser recompensada

3 La investigación en que se basa este artículo fue patrocinada por el Consejo Superior de Educación durante 2008.

4 El total de universidades en el país hasta la fecha es de 61 y 25 corresponden a universidades del Consejo de Rectores. 
positivamente a partir del cúmulo de experiencia adquirida, lo que redunda en mayor prestigio y mayores oportunidades de obtener más recursos e invitaciones para participar en decisiones de gran trascendencia en el campo de la educación superior (Bernasconi, 2008). Esto último constituye una diferencia significativa con relación a otras profesiones, en las cuales envejecer suele estar asociado a escasas posibilidades de seguir ascendiendo y mejorar las condiciones de empleo.

En este artículo se informa acerca de los principales hallazgos de la investigación sobre carrera académica en concordancia con los objetivos y las hipótesis preliminares establecidas.

En relación con el objetivo "conocer cuáles son las normas, principales objetivos y percepciones sobre carrera académica en universidades chilenas", los hallazgos revelan que las normas que guían el desarrollo de carrera académica se configuran sobre la base de una multiplicidad de factores, en los cuales convergen múltiples actores, ya sea individuales, institucionales o societales.

Las instituciones universitarias definen las normas que se traducen en el marco regulador de las exigencias, incentivos y condiciones de trabajo de los académicos. Estas normas giran en torno a un sistema de prestigio, en el que cada actividad y la posición en que se encuentra cada profesor tienen un valor asociado que guía el comportamiento, aporta el marco para el desempeño de funciones y establece códigos de comunicación entre los miembros de la comunidad universitaria. A su vez, este valor diferencia el trabajo académico y se relaciona con un determinado espacio en la estructura de jerarquía, con un valor simbólico que luego se convierte en un valor material.

La carrera académica se desarrolla bajo la forma de una competencia individual llevada a cabo por cada académico para cumplir con sus propios objetivos y los de la misma universidad. Esta competencia que sostienen los individuos consigo mismo, pero cuyo éxito se disputa dentro de la cultura de las instituciones y las disciplinas, hace que tanto los objetivos individuales como los institucionales converjan en un perfil de carrera académica cuya valoración más alta 
está asociada a la investigación. Consecuente con ello, las normas perseguidas y requeridas en diferentes grados por los académicos se basan en la publicación en revistas científicas especializadas (ISI ${ }^{5}$ y $\mathrm{SciELO}^{6}$, por citar las más requeridas), la participación en proyectos FONDECYT ${ }^{7} u$ otros de renombre internacional, un número mínimo de horas de dedicación a docencia de pre o posgrado ${ }^{8}$, grados académicos de nivel de doctorado y posdoctorado, entre otras.

Aquellos que por distintos motivos no siguen estas reglas se sitúan en espacios de menor reconocimiento académico, muchas veces con menores salarios y poca incidencia en la toma de decisiones.

Por otra parte, los objetivos de carrera académica o trayectorias de carrera profesional que los académicos se proponen recorrer se orientan principalmente a la creación de nuevos conocimientos y difusión de sus resultados. También se percibe entre los entrevistados el anhelo de desarrollar una carrera progresiva y en ascenso, orientada por el reconocimiento externo a su labor, así como también la posibilidad de obtener ventajas y beneficios, por ejemplo, percibir ingresos extra a sus habituales salarios, viajes al extranjero, apoyo institucional para el desarrollo de publicaciones o permisos sabáticos, por citar los más destacados. Si bien se constataron diferencias en los objetivos perseguidos, según el grado de preponderancia o cercanía otorgado a este ideal de carrera académica, en general, todos apuntaban a recorrer una trayectoria más o menos homogénea

5 Institute for Scientific Information.

6 Scientific Electronic Library Online.

7 Fondo de Ciencia y Tecnología de la Comisión Nacional de Ciencia y Tecnología (CONICYT) de Chile.

8 En todas las instituciones de nuestro estudio los académicos debían cumplir con un mínimo de horas de docencia y había un piso mínimo para todos los profesores con jornada completa que oscilaba entre dos y cuatro cursos por semestre. La variación en el número de cursos dependía del nivel de recursos económicos de las instituciones y departamentos. Además, los jóvenes, por lo general, tendían a tener mayores cargas de docencia que sus pares mayores. Un tercer factor estaba relacionado con los cargos administrativos y de desarrollo de investigación, porque las cargas de docencia podían disminuir según los cargos administrativos en que se encontraban los académicos o si estaban involucrados en algún proyecto de investigación con recursos externos, como fue el caso de quienes estaban realizando sus proyectos FONDECYT. Por último, hubo casos de académicos cursando sus doctorados a la vez que desempeñaban sus labores. Generalmente, la institución les apoyaba de manera parcial en el pago de arancel y en la disminución de cursos dentro del total de la carga docente exigida por cada institución. 
(con grados variables de éxito) en tanto intentaban alcanzar labores más relacionadas con investigación por sobre las de docencia o administración.

Respecto del objetivo de "indagar si existían diferencias según variables de tipo institucional (públicas/privadas; mercado competitivo/ no competitivo; volumen de investigación alto/bajo) o individuales (género, edad, disciplina que cultiva)", los principales hallazgos muestran que no hay diferencias sistemáticas en la percepción de lo que se entiende por carrera académica según la variable "tipo de institución", sino más bien según variables de tipo individual.

Se pensaba que habría diferencias significativas en la concepción de carrera académica según fueran instituciones públicas o privadas, ubicadas en mercados competitivos o no competitivos, o según altos o bajos volúmenes de investigación. En el caso de las universidades privadas, se consideraba que, en general, podrían estar más cercanas a un perfil docente, mientras que las públicas un perfil de profesorado más cercano a la investigación. La misma lógica para las universidades con altos y bajos volúmenes de investigación y aquellas ubicadas o no en mercados competitivos. Se suponía que el ideal de carrera académica asociado a un perfil de investigación estaría más presente en universidades ubicadas en mercados competitivos, así como también en aquellas con altos volúmenes de investigación. Lo opuesto como modelo de carrera académica se esperaba para la otra cara de estas instituciones con bajos volúmenes de investigación, ubicadas en mercados no competitivos.

Esta hipótesis fue falsada en la realidad, puesto que cualquiera fuera el tipo de institución y sus posibles combinaciones según tipos institucionales (universidad pública, con bajos volúmenes de investigación y ubicada en mercado competitivo, por ejemplo), el modelo de carrera académica era más o menos homogéneo.

La diferencia entre instituciones históricamente asociadas a un perfil de investigación con aquellas más cercanas a un perfil docente se relacionaba más con el número de profesores que detentaba este perfil dentro de una misma institución. En el caso de las primeras, este 
modelo se observaba como norma en una buena parte de la población académica, mientras que en las segundas el número de académicos que cumplía con este perfil era menor en cantidad. Lo cual, no obstante, no eliminaba el hecho compartido y reconocido por todos los tipos de instituciones sobre las tendencias hacia el desarrollo de carrera académica en el sistema universitario actual.

Por último, sobre el objetivo "establecer el grado de consistencia entre las normas (contexto institucional) y expectativas del profesorado universitario sobre las condiciones en que se desenvuelve y desarrolla la profesión académica en Chile hoy“, se pudo establecer en el análisis sobre los reglamentos de carrera académica de las instituciones universitarias un grado de consistencia significativo entre los reglamentos y los objetivos de desarrollo de carrera de los académicos. A su vez, estos documentos actuaban como puente entre ambas percepciones y dimensiones de la carrera académica, a saber, la visión institucional y la experiencia de vida traducida en eventos de vida personal de los académicos.

También se pudo observar la presencia de mínimas variaciones en los grados de consistencia entre ambas visiones según tipo de universidad pública o privada, y las diferencias estaban relacionadas sólo con el nivel de incentivo económico que ofrecía cada universidad a sus académicos. Por lo general tendía a ser superior en las universidades privadas y, en el caso de las universidades publicas, en los departamentos, escuelas o facultades de mayor prestigio, como Derecho, Ingeniería, Economía y Medicina.

\section{Método y casos}

Estas formulaciones se basan en la recopilación de información estadística y, principalmente, en 67 entrevistas realizadas durante el primer semestre del presente año en siete universidades, tanto metropolitanas como regionales.

La selección de las universidades se basó en criterios de régimen jurídico (pública o privada), volúmenes de investigación (alto o bajo) y mercado (competitivo o no competitivo) en el que se 
encontraban las universidades. Del total de las universidades en Chile fueron seleccionadas: Universidad de Chile, Universidad Tecnológica Metropolitana, Universidad Diego Portales, Universidad de La Frontera, Universidad Austral de Chile, Universidad de Concepción y Universidad de La Serena.

En la tabla 1 se ordenan las instituciones según las variables utilizadas:

Tabla 1

\begin{tabular}{|l|l|c|c|}
\hline $\begin{array}{l}\text { Tipo universidad } \\
\text { según régimen } \\
\text { jurídico: }\end{array}$ & $\begin{array}{l}\text { Volumen investigación (No FONDECYT } \\
\text { y publicaciones ISI x institución) }\end{array}$ & $\begin{array}{c}\text { Mercado } \\
\text { competitivo }\end{array}$ & $\begin{array}{c}\text { Mercado no } \\
\text { competitivo }\end{array}$ \\
\hline \multirow{3}{*}{ Pública } & Alto & $\begin{array}{c}\text { Universidad de } \\
\text { Chile }\end{array}$ & $\begin{array}{c}\text { Universidad de } \\
\text { La Frontera }\end{array}$ \\
\cline { 2 - 4 } & Bajo & $\begin{array}{c}\text { Universidad } \\
\text { Tecnológica } \\
\text { Metropolitana }\end{array}$ & $\begin{array}{c}\text { Universidad de } \\
\text { La Serena }\end{array}$ \\
\hline Privada & Alto & $\begin{array}{c}\text { Universidad de } \\
\text { Concepción }\end{array}$ & $\begin{array}{c}\text { Universidad } \\
\text { Austral de Chile }\end{array}$ \\
\cline { 2 - 5 } & Bajo & $\begin{array}{c}\text { Universidad } \\
\text { Diego Portales }\end{array}$ & $(0)^{9}$ \\
\hline
\end{tabular}

Los entrevistados se seleccionaron usando criterios de representatividad según tipo de área del conocimiento: 50\% de los entrevistados correspondieron a disciplinas relacionadas con ciencias naturales y exactas y el otro 50\% a áreas de humanidades, ciencias sociales y Derecho. Se intentó resguardar en la medida de lo posible una proporción equivalente a las cifras nacionales sobre profesorado universitario según género que, para 2007, era de 35\% de profesoras mujeres y $65 \%$ varones (CSE, 2007). Por último, la variable "tipo de jornada laboral" se constituyó en la variable de corte para la selección de

9 Este símbolo significa casillero vacío. No fue posible llenar esta casilla, pues no existe en esta categoría un tipo de universidad con escasos o nulos volúmenes de investigación que se ubique en un mercado no competitivo. "Mercado competitivo" es entendido como bajo número de instituciones en una misma región geográfica. Lo anterior podría explicarse en tanto es parte de la misma lógica de las instituciones privadas competir por atraer más recursos en el mercado académico, lo que las hace concentrarse en regiones en las cuales hay más demanda por educación superior y, por tanto, mayores posibilidades de atraer a un buen número de estudiantes. 
los profesores. Se decidió trabajar solamente con casos de académicos con dedicación completa a una universidad y que trabajaran en posgrado, porque se hipotetizaba que éstos estarían más involucrados en la carrera académica. Estas variables fueron significativas a la hora de acotar el universo de entrevistados: según cifras nacionales de 2007 (CSE), sólo 26\% de los profesores universitarios chilenos trabaja con jornada completa en una universidad.

Una vez definidas las universidades, la nómina de profesores para entrevistar en cada una se obtuvo a partir de la información sobre programas de posgrado disponible en los respectivos sitios web.

El objetivo de las entrevistas era conocer cómo se ha ido configurando la carrera académica en Chile, cuáles son los objetivos a los que se orienta y las expectativas y percepciones que tienen los profesores sobre el desarrollo de carrera académica dentro de sus respectivas instituciones.

En este artículo se intentará describir cómo se organiza y estructura la carrera académica, según las percepciones de los académicos sobre sus propias carreras, la relación con la universidad a la que pertenecen y las diferencias entre dichas percepciones según variables individuales como edad, género y disciplina. A partir de esta información se espera delinear la carrera académica como una trayectoria de vida, con hitos y ritos de pasaje claramente establecidos y reconocidos por la comunidad académica.

\section{Estructura y organización de la carrera académica}

La carrera académica se estructura sobre la base de un sistema de prestigio, ordenado por un paradigma que establece como parámetros de excelencia y evaluación la investigación basada en resultados publicables en revistas indexadas y la capacidad de atraer recursos y fama a las instituciones que respaldan a sus académicos (Jencks y Riesman, 1968).

La estructura se ordena en torno de principios de jerarquización de los miembros y códigos simbólicos de la comunicación, que orientan y regulan la acción, y moldean y dan forma a la institución 
universitaria. Es una "estructura estructurante", en palabras de Giddens, en tanto son los mismos académicos quienes, dentro de un marco institucional que les brinda la universidad, reproducen los códigos internos que dan sentido a las estrategias de relación con sus pares y superiores jerárquicos, así como a la motivación en torno al trabajo universitario. A través de sus prácticas, van reproduciendo la cultura universitaria, estableciendo funciones y obligaciones que pasan a ser internalizadas y, de ese modo, contribuyen a reproducir la estructura con cada acción.

El éxito en la carrera académica puede ser entendido como mejores oportunidades para obtener empleo en el mundo académico, alcanzar estabilidad a lo largo del tiempo, obtener incentivos a la productividad, salarios competitivos y, en muchos casos, posibilidad de viajar y tener un horario flexible.

Para recibir estos beneficios, los académicos deben competir por fondos externos de investigación, publicar en revistas de prestigio y hacer actividades de extensión que den visibilidad al trabajo personal y de la institución a la que pertenecen. Para gozar de las garantías del trabajo académico y de sus beneficios, los profesores necesitan cada vez más dedicar un tiempo de trabajo que excede las 44 horas a la semana, lo que convierte a la profesión académica en una actividad exigente en términos de dedicación horaria.

La organización de la carrera académica opera sobre la base de la cultura institucional universitaria, reflejada en la misión y visión, y distingue y ordena el trabajo a través de sus reglamentos que organizan la carrera del cuerpo académico en grandes categorías, las que, a su vez, corresponden a jerarquías que, en la mayor parte de los casos, se asocian también a rangos en la escala de sueldos.

Por otra parte, es posible encontrar un patrón similar para ordenar, clasificar, categorizar y jerarquizar a los académicos en las universidades privadas y públicas, tendiendo las primeras a asumir el mismo patrón que las instituciones públicas han tenido por años. Esto, a su vez, es parte de la misma tendencia latinoamericana (Balbachevsky, 2008). Así, se configura un modelo homogéneo de 
jerarquización y se establece un lenguaje común aun entre diferentes instituciones universitarias.

Dentro de la estructura universitaria, estas categorías sirven como mecanismo de distribución de los académicos en un sistema jerárquico y, a la vez, para establecer valorizaciones diferenciadas entre los miembros de la comunidad científica. Por parte de las instituciones, las diferentes categorías llevan asociadas exigencias diferenciadas en la evaluación del desempeño y para la promoción de sus académicos.

Las categorías encontradas en el caso chileno son la de Profesor Asistente, Profesor Asociado y Profesor Titular; en algunas universidades también fue posible encontrar la categoría de Profesor Instructor en la base del sistema.

Según el orden de importancia y prestigio, las jerarquías se ordenan en forma de pirámide, quedando los profesores de mayor relevancia en la cúspide y los considerados con menos experiencia y poder en la base, siendo más numerosos estos últimos. Por último, existe también una correspondencia entre la estructura de salarios y el prestigio: sueldos más altos para las más altas jerarquías.

Durante muchos años en Chile, aun en universidades públicas de gran tradición, la categoría de Profesor Titular estaba asociada principalmente a los años de servicio docente dentro de la institución. Si bien esto sigue ocurriendo, cada vez más está cambiando hacia un mayor reconocimiento a la trayectoria en investigación, formación de discípulos en pre y posgrado y reconocimiento al trabajo tanto nacional como internacional.

La autoridad y el prestigio del que goza un Profesor Titular son ampliamente reconocidos $y$, por tanto, codiciados por quienes se encuentran en las categorías inferiores. Además, en la mayoría de los casos, los cargos directivos (decanatos, vicerrectorías y rectorías) sólo pueden ser elegidos entre los miembros titulares o asociados. Estas posiciones de poder reflejan lo más alto de la estructura jerárquica y sirven también como motor de competencia y modelo ideal para los profesores: alientan un ideal de carrera académica que, atenida a las normas y basada en los méritos individuales, posibilitan ascender 
en la estructura y habilita para alcanzar puestos de mayor prestigio y remuneración.

Dentro de la clasificación y jerarquización del cuerpo académico, también es posible encontrar categorías que, en la mayoría de los casos, son denominadas A, B, C y D, siendo A la de mayor importancia y $\mathrm{D}$ la de menor. Estas categorías introducen distinciones más finas en cada una de las jerarquías, asociadas al número de años, por ejemplo, que debe cumplir un profesor para pasar de una letra a otra antes del cambio de categoría. Este elemento, si bien mucho más complejo que lo que aquí se menciona, es bien manejado por los profesores que, al ser consultados, detallan con gran conocimiento la diferencia entre "jerarquización" y "categorización".

El paso de una jerarquía a otra no significa necesariamente un salto cuantitativo en las remuneraciones de los profesores universitarios, sino más bien implica un cambio simbólico dentro de un sistema de prestigio. Esto otorga mayor respeto y autoridad a los académicos por parte de las instituciones y cuerpo directivo. Tal como señalaron académicos de algunas universidades públicas, el cambio de una jerarquía o categoría a otra superior no significa grandes cambios en términos salariales. Muchos de ellos concordaron en que las motivaciones para intentar la promoción eran más en el orden simbólico del prestigio y reconocimiento que en el material o económico.

\section{Trayectorias académicas: percepciones y modelos múltiples}

Al hablar de percepciones hacemos referencia al proceso mediante el cual los individuos otorgan significado al medio que los rodea. El concepto de "percepciones" ha sido desarrollado y debatido ampliamente en el ámbito de la psicología; aquí se considerarán las percepciones desde una óptica más sociológica. Las percepciones serán entendidas como el proceso de interpretación y mediación de la realidad que hacen los sujetos para relacionarse con el medio donde se insertan, lo que les permite codificar la realidad y, de ese modo, integrar la información que proviene del mundo exterior con 
su experiencia y trayectoria, configurando un mundo con valores, ideales y maneras de estar en el mundo específicos.

Tanto las percepciones como las normas y objetivos dan un marco de referencia preliminar para descifrar lo que es, vista desde los propios sujetos, la carrera académica. Los objetivos pueden ser entendidos como la trayectoria de carrera profesional que los académicos se proponen recorrer, a la vez que responden a los requisitos de pertenencia y desempeño que definen y modelan lo que es ser académico, ya sea por definición de las instituciones mismas o por la fuerza de la demanda internacional en un contexto histórico y económico modelado por la sociedad del conocimiento.

En este artículo las percepciones de los académicos están estructuradas en función de las trayectorias de vida constituidas por "eventos" que configuran y atraviesan la carrera académica, y se identifican en etapas que comienzan con el ingreso, siguen con el desarrollo y la promoción y terminan con el retiro.

Para efectos de una mayor claridad, las percepciones se estructuran primero en función de la carrera académica, vista como eventos dentro de una trayectoria de vida, y luego se introducen las variables que originan diferencias en las percepciones, como las de género, edad, tipo de disciplina e institución.

\subsection{Los inicios: el doctorado como rito de iniciación}

¿Cómo han ingresado los profesores a la academia? ¿Cómo han iniciado sus carreras? A partir de las entrevistas, se puede observar que, desde los orígenes, las carreras empiezan a diferenciarse y muchas de ellas están también relacionadas con la época histórica, las oportunidades que ésta genera y la edad ${ }^{10}$ de los académicos.

Para muchos, el obtener el grado de doctor opera como un rito de iniciación en el mundo académico del Chile actual y su obtención se expresa de dos maneras, según sea el caso: para quienes, no habiendo

10 En esta investigación el corte de edad para cada categoría se definió de la siguiente manera: joven (30-39 años); adulto semisenior (40-50 años); adulto senior (51 años y más). 
ingresado aún a la academia, estar en posesión de un doctorado (o estar ad portas de obtenerlo, como en la última etapa de la tesis y su defensa) abre la puerta hacia ella, generando así mayores y mejores oportunidades de conseguir un puesto de trabajo con estabilidad y todos los incentivos que ofrecen gran número de universidades; para aquellas personas que, estando afiliadas a una institución universitaria, ingresaron a ella sin el doctorado, obtener este grado significa, por un lado, mejorar sus condiciones de trabajo (como el ascenso de una categoría a otra) y, por otro, tener acceso a un contrato estable y de larga -si no indefinida-duración.

Por ejemplo, entre los jóvenes que se han incorporado en años recientes a la universidad es posible encontrar la siguiente afirmación:

"Llegué por concurso, vi el aviso en el diario que necesitaban un profesional en mi campo con grado de doctor, y deseable con posdoctorado, entonces postulé y quedé" (académico, joven, universidad privada).

Otro académico, que solamente este año había ingresado a trabajar a la universidad, sostuvo:

"El doctorado se está considerando como un requisito de entrada. El mercado está siendo cada vez más competitivo" (académico, joven, universidad privada).

Por otra parte, los de mayor edad sostuvieron que, en sus inicios de carrera, siendo estudiantes destacados durante sus carreras de pregrado, empezaron a ser cooptados por sus profesores, primero como ayudantes, y luego se fueron quedando en la institución al abrirse ciertos espacios que ellos empezaron a ocupar. Estaban en el momento y el lugar apropiados para hacerlo y así pudieron obtener una posición gracias al respaldo de un profesor mentor:

"Mis profesores me abrieron espacios para poder trabajar. Me ayudaron mucho para poder comenzar" (académico, senior, universidad pública). 
"Entré a trabajar aquí por relevo, por ausencia, omisión" (académico, semisenior, universidad privada).

Ellos fueron haciendo carrera pasando por todas las etapas antes de llegar a la consagración, empezando en una época donde se podía hacer carrera o al menos iniciarla, teniendo sólo el grado de licenciatura.

"Fui escalando desde abajo" (académica, senior, universidad privada).

Estos que empezaron sus carreras tempranamente han debido pasar por todas las categorías de la clasificación y, a medida que ha transcurrido el tiempo y las exigencias así lo han requerido, han debido comenzar sus procesos de perfeccionamiento estando 'adentro'. En estos casos, muchos han recibido el apoyo institucional para hacer el doctorado o para realizar sus estadías de investigación en otras instituciones, que en algunos casos se traducirían posteriormente en el posdoctorado.

"Yo salí a hacer el doctorado siendo viejo, a los 45 años.

Me tomé del último coche del tren, digo yo, porque después empezaron a otorgar permisos pero sólo hasta los 35 años" (académico, senior, universidad pública).

Una diferencia generacional importante, en este aspecto, es lo que señala un académico en relación con el doctorado:

"Antes el doctorado era el punto cúlmine de la carrera; hoy es el punto de entrada" (académico, joven, universidad privada).

Si bien todavía es posible encontrar actualmente casos en que estudiantes destacados han empezado con sus carreras tempranamente y dentro de una misma institución, lo cierto es que esto se va haciendo válido no ya en la licenciatura, sino más bien en el magíster o doctorado. 


\subsection{Elementos destacados para avanzar en la carrera}

La etapa que sucede a los orígenes se relaciona con el desarrollo de la carrera y sus distintas estrategias. ¿Cómo comienza a hacer carrera un profesor en la academia?

"El foco principal de una carrera académica está basada en la investigación. Probablemente 20 años atrás esto no estaba tan claro" (académico, senior, universidad privada).

La cita anterior grafica claramente lo que ocurre actualmente en el sistema universitario chileno, y que a su vez es parte de un modelo de carrera basado principalmente en el desarrollo de la investigación y la difusión de sus resultados a través de la publicación.

La siguiente afirmación parece radical, pero contiene un gran sentido de verdad en el desarrollo de carrera académica:

"Tú eres en la medida que publicas" (académico, senior, universidad privada).

Esto es parte de una tendencia hacia un modelo de carrera cada vez más globalizado y homogéneo, y reconocido por todos los miembros de la comunidad científica. Es así como cada vez es más evidente que el desarrollo de carrera académica ha de cumplir con un perfil de investigación, que requiere competir por fondos de investigación a la vez que publicar en revistas de prestigio.

Este modelo, si bien no estaba tan claramente establecido, sí era habitual de la práctica vinculada a las áreas de las ciencias naturales y exactas, en las cuales, aun los profesores senior, e incluso quienes han sobrepasado la edad de la jubilación, desarrollaron su vida académica en torno a la investigación y la publicación, obtuvieron sus doctorados tempranamente y se dedicaron a la creación de programas de posgrado de más larga data en el país.

"Los profesores más relevantes son los que se dedican a la investigación. La investigación da mayores méritos, da prestigio, está rodeada de un aura de reconocimiento" (académico, senior, universidad pública). 
En este contexto, los profesores con este perfil fueron considerados los más relevantes dentro de las instituciones y, en muchos casos, clasificados en las más altas jerarquías y con sueldos más elevados. Al cumplir con un perfil de excelencia dentro de las instituciones, comenzaron también a ser parte de los comités de selección y promoción de los académicos, constituyéndose ellos y sus respectivas disciplinas en fuentes de gran prestigio y poder dentro del ámbito científico.

"Hay gente que siente que aquellos que estamos en la investigación estamos discriminados positivamente dentro de la carrera académica" (académico, senior, universidad pública).

En las ciencias sociales, las humanidades y el Derecho el desarrollo de carrera estuvo largamente asociado a un perfil docente, donde por décadas la investigación y la publicación no fueron consideradas el motor. Para las nuevas generaciones en estas áreas es totalmente diferente, ya que empiezan a mostrar grados académicos más elevados, como el doctorado o posdoctorado, y compiten por fondos de investigación y por la publicación en revistas especializadas dentro de su campo.

\subsection{La promoción y el éxito}

La promoción es la etapa siguiente en el desarrollo académico. El éxito se consigue siguiendo los patrones de evaluación establecidos por las instituciones, los cuales están basados principalmente en los niveles de perfeccionamiento y de productividad, medida ésta en el número de proyectos adjudicados y en publicaciones de relevancia para la disciplina. En Chile esto se traduce principalmente en proyectos FONDECYT y publicaciones ISI y SciELO, que marcan la pauta de lo considerado de mayor valor en gran parte de las universidades:

"Esta universidad no valora ninguna investigación que no sea la que uno articula con FONDECYT o una de carácter internacional" (académico, senior, universidad pública). 
Ciertas críticas consideran que los criterios de evaluación han puesto el acento en el número de los proyectos y publicaciones más que en la calidad del desempeño académico:

"El sistema de evaluación se ha vuelto más cuantitativo y sería deseable que volviera a ser más cualitativo, como antes" (académico, semisenior, universidad privada).

La promoción está asociada al éxito en las actividades llevadas a cabo por un profesor, medido a través de los sistemas de evaluación que las instituciones establecen para normar el trabajo de sus académicos. Esto, a su vez, se asocia con un nivel de recompensas y habilita a los académicos para moverse al interior de la estructura hacia posiciones más privilegiadas que premian su buen desempeño.

"Si no publico no puedo ascender de categoría, ni recibo la asignación" (académica, senior, universidad privada).

Se crean así distinciones entre las diferentes funciones que, se supone, debe cumplir un académico, a saber: docencia, investigación y extensión, a las que crecientemente se agregan las labores de administración y gestión. Ellas, a su vez, tienen diferentes valorizaciones: la investigación y el número de publicaciones se convierten en el patrón oro de la academia.

"Lo que más pesa en el cambio de jerarquización son las publicaciones y la investigación; no son los únicos criterios, pero son los que más pesan. La docencia, por ejemplo, casi no existe... Entonces ahí está un poco la desventaja que tienen esos colegas que se dedican principalmente a la docencia" (académico, semisenior, universidad pública).

No está tan claro cómo el sistema reaccionaría ante un profesor con mal desempeño. Las razones que podrían explicar en parte esta debilidad se basan en que los sistemas de evaluación son relativamente nuevos y, además, en algunas instituciones públicas resulta extremadamente engorroso despedir a un profesor mal evaluado. Pareciera no suceder lo mismo en el caso de las privadas, aunque tampoco ha sido de conocimiento entre nuestros entrevistados que 
algún hecho de esta naturaleza ocurriera. En aquellos casos conocidos en que algún profesor ha sido alejado de la institución no ha sido por motivos de baja productividad, sino por conductas inapropiadas, por ejemplo, acoso sexual.

\subsection{El retiro o término de la carrera académica}

Durante el transcurso de la investigación se pudo constatar que varios de los entrevistados sobrepasaban la edad legal de jubilación: en el caso de las mujeres corresponde a los 60 años; en el de los varones, a los 65. Todos quienes sobrepasaban esa edad señalaron que seguirían trabajando "hasta que la cabeza les siguiera funcionando" y que no tenían ninguna intención de jubilarse en el corto plazo. Ello en parte por la gran satisfacción que sienten realizando sus labores académicas, pero también por el hecho económico que restringiría hasta en más de $50 \%$ sus actuales ingresos una vez jubilados.

"En esta institución no hay incentivos para jubilar" (académico, senior, universidad pública).

"Si acaso esa gente jubila va a quedar percibiendo el $40 \%$ de su sueldo, y esa es otra de las razones por la cual hoy día no hay un tiraje en el sistema universitario chileno" (académico, semisenior, universidad pública).

La jubilación empieza a ser un problema de creciente interés para el gobierno universitario, toda vez que se observa, especialmente en el caso de las universidades públicas, que no existen incentivos para el retiro de los académicos más antiguos, y que muchas de las plantas académicas están cargadas con profesores que sobrepasan la edad legal de jubilación.

"Hace un par de años se dieron cuenta que la planta estaba envejecida. Entonces, se creó un modelo de retiro donde se dio un incentivo para jubilar. Con esto se ha permitido una cierta renovación en los cargos" (académico, senior, universidad privada).

Algunas instituciones han ofrecido ciertos incentivos pero, ante la escasez de recursos, los beneficios se han considerado muy débiles 
y poco atractivos para animar a los académicos a jubilar. Se reconoce que está pendiente una política pública en esta materia ${ }^{11}$.

\section{Diferenciación de los modelos de carrera académica según edad, género y disciplina}

Puesto que uno de los supuestos de la investigación era descubrir si existían o no diferencias significativas al momento de percibir lo que era la carrera académica, según variables individuales o institucionales, cabe señalar que una de las hipótesis preliminares que orientaban la investigación se refería a que las mayores diferencias (y conflictos) se encontrarían en función de variables individuales y especialmente las referidas a la variable género. Ello en parte por la literatura encontrada y por hallazgos de una investigación anterior (Berríos, 2005). No obstante, se puede señalar que las mayores diferencias en el desarrollo de las carreras académicas no están en el género, sino en las variables edad y disciplina.

\subsection{Edad: jóvenes emprendedores, adultos consagrados}

Se pudo constatar que la variable edad fue una de las que más incidía en diferenciar las percepciones sobre la carrera académica, especialmente en ciencias sociales, humanidades y Derecho, aunque también fue posible encontrarla en ciencias naturales y exactas, pero por razones diferentes.

En el caso de las primeras, los jóvenes que recién se incorporan a las filas de la academia experimentan cierto rechazo de parte de sus colegas mayores, debido a que los primeros ingresaron teniendo el grado de doctor y con publicaciones o proyectos de investigación a su haber. Sus mayores, no estando socializados en el paradigma de la

11 Fue interesante conocer el caso de la Universidad de Concepción respecto de la edad de jubilación de las mujeres (60 años), en la cual, gracias a las gestiones de la Asociación de Académicas, se consiguió la igualdad en la edad con los varones a los 65 años. La institución estaba ofreciendo un incentivo a la jubilación a las personas en edad de hacerlo, que consistía en la entrega de un 20\% de sueldo adicional a la pensión, lo que se denominó "renta vitalicia". Así, las mujeres quedaron habilitadas para trabajar hasta los 65 años para tener derecho a esta renta vitalicia. Tanto hombres como mujeres que no quisieran acceder a este beneficio lo perderían, aunque, por otra parte, esto les permitiría seguir trabajando en la universidad, aunque sólo por un determinado número de años. 
investigación ni en posesión de los grados académicos que exhibían estos jóvenes, resentían que estos elementos pudieran mermar su autoridad:

"Hay una generación de académicos más viejos que siente temor ante los jóvenes, que además vienen más preparados" (académica, semisenior, universidad privada).

En el caso de las ciencias naturales y exactas, los profesores más antiguos contaban con grados de doctor y larga experiencia en investigación; por lo tanto, estos elementos no constituían un motivo de temor para ellos. Las razones del conflicto generacional en este caso parecen relacionarse con el ímpetu de los jóvenes por intentar cambiar y modernizar ciertas prácticas consagradas:

"El ímpetu y la creatividad no es deseable en los jóvenes" (académica, joven, universidad privada).

A su vez, los profesores jóvenes sienten que sus mayores tienden a minimizar sus esfuerzos o iniciativas emprendidas:

"Los primeros años te tratan como chiquitito, sienten que te están haciendo un favor al apoyar tus iniciativas" (académico, joven, universidad privada).

Por otra parte, los académicos que, habiendo pasado su etapa inicial en la carrera académica, se ubicaban en la generación intermedia (entre 40 y 50 años), plantean que en ellos descansan los mayores niveles de productividad y que pese a esto sus contribuciones no son recompensadas como esperan. Uno señaló:

"La mayor productividad se concentra entre la segunda y tercer categoría de la clasificación, no en la de los profesores titulares" (académico, semisenior, universidad privada).

En el caso de los profesores senior, el tema de la edad no aparece como parte de sus preocupaciones en este ámbito, aunque sí reconocen cierta inquietud por el poco aprecio a sus trayectorias que, 
en ciertos casos, los jóvenes doctorados 'recién llegados' muestran. Más bien la actitud que en ellos se pudo observar fue de apoyo al reclutamiento de jóvenes que trajeran aires renovados al trabajo de la universidad.

\subsection{Género: productividad vs. vida privada}

Una mirada panorámica de la composición del cuerpo académico señala una clara supremacía de los varones por sobre las mujeres. Para el caso chileno, la diferente distribución por sexos puede apreciarse en el gráfico 1:

Gráfico 1. Distribución de docentes por jornada y sexo

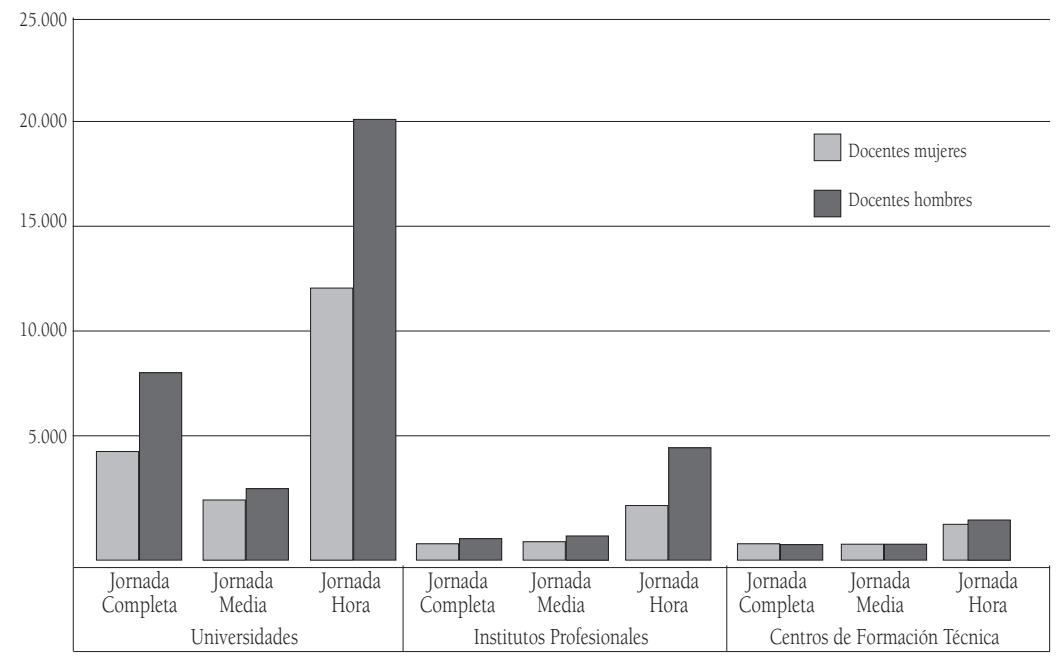

Fuente: Consejo Superior de Educación, INDICES, 2008.

Esta distribución muestra que las mujeres aún siguen siendo minoría dentro del mundo académico. Con relación a la carrera académica, las relaciones de género afectan el rendimiento no sólo de mujeres, como se verá en lo que sigue. Según dos académicos, la vida académica se ve influida desde diferentes frentes por la vida personal, lo que afecta a hombres y mujeres:

"Si una persona se divorcia, baja la productividad: tu vida está relacionada con el trabajo" (académico, senior, universidad privada). 
"No hay equilibrio entre lo científico y la vida privada... tú aquí ves colegas que vienen a trabajar al laboratorio los fines de semana... es que la investigación nunca para, no tiene tiempo" (académico, semisenior, universidad privada).

Las mujeres mencionaron que en sus carreras académicas no habían sentido discriminación ni habían sido objeto de tratos diferenciados por parte de sus colegas. Más bien negaron que existiera algún tipo de trato especial hacia ellas, en sentido positivo o negativo. Al ser interrogadas más en profundidad, algunas pudieron encontrar algunas diferencias -traducidas en desventajas-. El doctorado parece presentar mayores desafíos para ellas:

"Es mucho más difícil para una mujer poder terminar el doctorado" (académica, joven, universidad privada).

"Tuve dificultades para doctorarme, por razones de tiempo, fundamentalmente por el hecho de ser madre y no poder entonces dedicarme $100 \%$ a lo profesional" (académica, semisenior, universidad privada).

En el caso de las académicas dedicadas a la investigación, la maternidad impactó significativamente sus carreras, en tanto vieron afectado su nivel de productividad.

"(cuando tuve mis hijas) mi carrera se truncó por un tiempo, los viajes al extranjero bajaron mucho... llevarlas afuera era muy caro; lo mismo para su seguridad mientras yo estaba en el trabajo de investigadora visitante" (académica, senior, universidad privada).

"Las lagunas (vacíos o bajas en la productividad) son súper mal miradas en cualquier profesión, y las mujeres las tenemos cuando tenemos nuestros hijos" (académica, senior, universidad pública).

Interesante es el relato de una destacada científica que convirtió la maternidad en un incentivo para aumentar su productividad, aunque también reconoce que estuvo dispuesta a esperar para tener 
un hijo y que decidió ser madre una vez que terminó su doctorado y completó el posdoctorado:

"A veces las mujeres nos demoramos más en llegar a la cima” (académica, senior, universidad privada).

Otro ámbito de las relaciones de género que se puede destacar a través de las entrevistas se refiere a quienes cumplen el rol de jefes de hogar y proveedores dentro de las familias. Tanto en varones como en mujeres, los profesores reconocían que habían sido más proclives a aceptar cargos administrativos de responsabilidad porque esto implicaba agregar ingresos extras a su salario habitual como académicos. Por lo general, los cargos administrativos tienden a ser evadidos por aquellos que se dedican mayoritariamente a la investigación, porque consideran que son muy exigentes y demandantes en términos de tiempo y energías.

\subsection{La cultura de las disciplinas: ciencias dominantes y ciencias subordinadas}

La carrera académica también encuentra sus puntos de tensión cuando se introduce la variable "disciplina" o "área del conocimiento". Quienes trabajan en áreas relacionadas con ciencias naturales y exactas tienen ventajas comparativas respecto de ciencias sociales, humanidades y Derecho. Ello porque en su mismo quehacer se practica la investigación y la publicación. No es un requerimiento externo (como suele suceder en los últimos años) a las ciencias sociales y humanas y al Derecho. Por tanto, estas últimas deben competir no sólo por un entrenamiento en estas habilidades, sino también por entrar en las lógicas del trabajo científico y del reconocimiento.

Uno de los elementos destacados a partir de las entrevistas fue descubrir cómo opera el trabajo de los académicos dedicados a las ciencias naturales y exactas frente al de aquellos dedicados a ciencias sociales, humanidades y Derecho. En el caso de las primeras, el trabajo en equipo es una de las características base de su estilo de trabajo. El trabajo en equipo multiplica las oportunidades para que el nombre de un investigador aparezca en una publicación. Además, en estas ciencias los hallazgos son parte de una cadena: se basan en trabajos previos y son antecedentes para trabajos futuros. 


\begin{abstract}
"En las ciencias duras todo el conocimiento está concatenado... por peldaños vamos construyendo el conocimiento" (académico, senior, universidad pública).
\end{abstract}

Esta cadena, a su vez, se expresa en las citaciones, consideradas como un indicador de relevancia e impacto del trabajo de los investigadores.

En las ciencias sociales, las humanidades y el Derecho las publicaciones tienden a tener un autor o dos, y una frecuencia menor; de modo que la productividad medida a través de los indicadores convencionales resulta inferior y más débil que el de las 'ciencias duras'. La misma dificultad se observa en relación con las citaciones.

Estas diferencias disciplinarias generan una gran brecha en los niveles de productividad y producen consecuencias diferenciadas al momento de evaluar. Los académicos de las ciencias sociales, las ciencias humanas y el Derecho tienen menos publicaciones e investigaciones en comparación con los provenientes de las ciencias químicas o biológicas, por ejemplo. Ello se traduce en que, salvo contadas excepciones, no son invitados a formar parte de los comités donde se deciden las promociones de los académicos y no alcanzan la titularidad con la misma frecuencia que los provenientes de las ciencias duras.

\title{
5. A modo de conclusión
}

En el ámbito de las percepciones sobre carrera académica, los hallazgos muestran que las percepciones varían más por razones individuales (género, edad y disciplina) que institucionales (pública/privada, mercado competitivo/no competitivo, volúmenes alto/bajo de investigación) y dan cuenta de distintos modos de hacer carrera académica. No obstante la diversidad de modelos de carrera académica observados, se comparte la valoración mayor que representa la investigación dentro del sistema de prestigio. El ideal de carrera académica es compartido por todos, aun cuando no todos se ajusten a estos estándares o estén de acuerdo con seguir este 
patrón de trayectoria profesional. Del lado de las instituciones, este ideal asociado a la investigación también es compartido, y es posible observar que se recrea un sistema de incentivos y recompensas para estimular a sus académicos a seguir por este camino.

Las mayores diferencias en las percepciones sobre carrera académica se encontraron en torno a las variables individuales de "género", "edad" y "disciplina" que cultivaba cada académico.

En el caso de la variable "género", si bien se esperaba encontrar diferencias en las concepciones sobre carrera académica según fueran académicos varones o mujeres, la realidad mostró una aparente igualdad entre ambos sexos, mientras que las diferencias se encontraron en la evaluación de las propias carreras. Para las mujeres se observó que presentaban mayores dificultades para un desarrollo de carrera exitoso debido sobre todo a razones asociadas con la maternidad, por lo general en la etapa inicial más productiva de las académicas. Esto hace que las académicas deban compartir su tiempo entre el 'laboratorio', la familia y el 'biberón', lo que en definitiva se traduce en mayor tiempo para alcanzar los mismos resultados de éxito que alcanzan los varones en la misma etapa del ciclo vital. En lo hechos, esto implicó -según el relato de las propias mujeres- perder la competencia por un cargo frente a un colega varón de la misma generación, lo que sin duda retrasaba muchos de los pasos necesarios para seguir progresando y avanzando en la carrera académica. Los varones destacan la dificultad para conciliar el mundo público del trabajo con el privado, donde este último afectaría los niveles de productividad.

En relación con la variable edad, fue notable la diferencia entre las generaciones mayores y las más jóvenes e intermedias; y lo fue aún más al combinarse con la variable disciplina. La mayor diferencia encontrada en la concepción y seguimiento del modelo de carrera académica fue entre los jóvenes y adultos de las disciplinas asociadas a las ciencias sociales, humanidades y Derecho. Los jóvenes y la generación intermedia, por lo general, estaban socializados bajo el paradigma de la productividad científica basada en la investigación y las publicaciones, y detentaban grados académicos más elevados, como los de doctorado o posdoctorado, cuestiones que, en general, 
no se observaban en relación con las generaciones más antiguas. Esto marca una gran distancia entre ambas generaciones y en los jóvenes se advirtieron mayores ventajas comparativas para conseguir el éxito y promoción en sus carreras por sobre aquellos profesores antiguos que, aun teniendo muchos años de docencia dentro de la institución, no podían equipararse con el nivel de productividad en investigación presentado especialmente por las generaciones intermedias -en nuestro estudio, correspondiente a los académicos entre los 40 y 50 años de edad.

En el ámbito de las disciplinas, las diferencias encontradas fueron significativas entre las disciplinas pertenecientes a las ciencias naturales y exactas versus las ciencias sociales, humanidades y Derecho. Si bien las diferencias se tienden a acortar en la actualidad, permanece aun en el imaginario simbólico de las universidades que las últimas disciplinas están más cercanas a un perfil académico docente, mientras que las primeras encarnarían en sí mismas el modelo de investigación. Pese al predominio de esta imagen, la realidad actual muestra que la brecha tiende a acortarse, aunque todavía permanece el predominio de las 'ciencias duras' en la esfera de la captación de recursos económicos, adjudicación de concursos de investigación y en mayores niveles de publicación en revistas de gran prestigio y reconocimiento científico.

En suma, la carrera académica es difícil de definir bajo la forma de un solo modelo. Como nunca antes en la historia de las universidades, éstas habían estado tan poderosamente sujetas a las tendencias del predominio de la universidad orientada a la investigación y como nunca antes los profesores universitarios habían estado presionados para alcanzar logros en su carrera sobre la base de logros asociados predominantemente a la investigación y publicación. Lo cual ha tendido a intensificar y recargar las cargas de trabajo para aquellos dedicados a estas tareas.

Pese a las mayores exigencias que las instituciones dirigen a los académicos, existe un alto grado de satisfacción con el trabajo académico por parte de los profesores. La complacencia que otorga el descubrimiento de algún hecho científico o el avance dentro de la 
disciplina se constituye en un poderoso motor de trabajo y motivación, cuyos frutos traen prestigio a los académicos. 'El reconocimiento vale oro' en la academia y, tal como sostuvieron algunos académicos, a veces sobre este principio se explica el que, en algunos casos, los profesores estén dispuestos a ganar menos dinero trabajando para la academia en comparación con lo que podrían ganar en el mercado de trabajo industrial o empresarial.

No obstante el sistema universitario chileno puja hacia un perfil de investigación, en nuestro estudio no encontramos académico alguno que estuviera dedicado exclusivamente a esas labores. La norma fue encontrar profesores de jornada completa que dedicaban al menos un tercio de su carga horaria a la docencia. El resto del tiempo tendía a ser distribuido en labores administrativas o de política interna de la universidad e investigación.

Queda pendiente la presentación de los resultados desde la visión normativa que establecen las instituciones universitarias sobre carrera académica, y el grado de convergencia de los objetivos individuales de carrera con los que persiguen las instituciones. Esta visión normativa se puede encontrar en la interpretación de los reglamentos de carrera como mecanismos de coordinación y autorregulación de las instituciones en relación con la conducción del cuerpo académico. Los hallazgos en este ámbito no hacen sino confirmar lo que la literatura especializada señalara hace casi treinta años para el caso norteamericano: sin una dedicación completa de los profesores a la universidad, ésta no podrá llegar a ser efectiva (Clark, 1979). Por tanto, la carrera académica es central para el éxito de cualquier universidad (Altbach, 2007).

Agradezco a quienes gentilmente accedieron a ser entrevistados y que compartieron con la investigadora a veces horas de conversación. Agradezco también a mis ayudantes de investigación por su destacada y dedicada labor durante todo el periodo de trabajo de campo. Al Consejo Superior de Educación, mi reconocimiento por la selección de esta propuesta de investigación y el apoyo económico para realizarla, así como también a mi supervisor por su orientación y continuo estímulo a seguir desarrollando investigación sobre esta materia. 


\section{Referencias bibliográficas}

Altbach, P. \& Balán, J. (Eds.) (2007) World Class Worldwide: Transforming Research Universities in Asia and Latin America. Baltimore, MD: Johns Hopkins University Press.

Balbachevsky, E. (2008) Experiencias de centros de pesquisa. Simon Schartzman organizador. Cap. Incentivos y trabas al emprendimiento académico en América Latina. En: Universidades e desenvolvimiento na America Latina.

Bernasconi, A. (2008) La profesionalización de la Academia en Chile. Calidad en la Educación 28: 15-27.

Bernasconi, A. (2007) Are there research universities in Chile? Altbach, Philip G. and Balán Jorge (Eds.) World Class Worldwide: Transforming Research Universities in Asia and Latin America. Baltimore, MD: Johns Hopkins University Press.

Bernasconi, A. (2006) Breaking the institutional mold: faculty in the transformation of Chilean higher education from the state to market. Meyer, H.D. \& Rowan, B. (Eds.) The New Institutionalism in Education. Albany, NY: SUNY Press, 2006.

Berríos, P. (2008) Normas y percepciones sobre carrera académica en Chile. Calidad en la Educación 28: 40-52.

Clark, B. (Ed.) (1979) The academic profession. National, Disciplinary, and Institutional Settings. Berkeley and Los Angeles, California, University of California Press.

Consejo Superior de Educación (2008) INDICES 2008 [en línea] Santiago de Chile, CSE. Disponible en: http://www.cse.cl

Consejo Superior de Educación (2007) INDICES 2007 cap. distribución de docentes por jornada y género por tipo de institución [en línea] Santiago de Chile, CSE. Disponible en: http://www.cse.cl

Gil-Antón, Manuel, et al. (1994) Los rasgos de la diversidad. Un estudio sobre los académicos mexicanos. México, D.F: Universidad Autónoma Metropolitana, Unidad Azcapotzalco.

Jencks, Ch. \& Riesman, D. (1968) The Academic Revolution. Garden City: Doubleday. 